\title{
Management Practices in Hospital Administration: A Study of the Challenges Faced by the Healthcare Organizations in South India
}

\author{
Bindi Varghese*
}

\section{Abstract}

This paper accentuates the need for quality assurance and standardization norms for hospital administration which is the need of the hour. Lack of effective administration practices in the hospital and hospitality sector necessitate the need for a total quality management approach in the Healthcare Sector. Application of quality control systems is a vital aspect that hospitals in South India cannot disregard. It would lead the South in a new direction by ensuring quality and enhancing customer satisfaction. Hence, this paper makes an attempt to understand the hospital management practices in South India effectively. The research addresses Medical Tourism as a 'cost effective' private medical care initiative in collaboration with the tourism industry for patients needing surgical and other forms of specialized treatment. This process is being facilitated by the corporate sector involved in medical care as well as the tourism industry - both private and public. There is also a constant effort taken by corporate hospitals to support medical tourism to its fullest potential. India today has copious opportunities to compete with other developed nations and building a quality health care system of its own.

* Assistant Professor, Department of Tourism Studies, Christ University, Bangalore, India 


\section{Introduction}

The subject of travel is exciting and fascinating, as travel and tourism is a global phenomenon. It is critical to address the diverse and mounting challenges in the Travel and Tourism sector, as it remains a critical economic sector worldwide and one that provides significant potential for economic growth and development internationally. There are enormous contributions from this sector as it is an important driver of growth and prosperity, particularly within developing countries (Woodman, 2007). As times are changing and so are the demands and expectations of the travellers who are endlessly in search for different experiences, different adventures, different lifestyles which have paved the way for various concepts, and defining different paradigms in the arena of tourism. This emerging sector offers an array of travel services benchmarking India at a global level, with its products like adventure, wildlife, historical monuments, culture and heritage, nature, pilgrimage and so on. Medical tourism is an upcoming concept and a growing phenomenon meeting the need of the hour (Theobald, 1998). India to a large extent is also been branded for its wellness and surgical competency. Medical patrons across India look forward for high-end medical facilities with value added services often referred to as co-ordinated services.

Co-ordinated services are offered by the hospitality sector as a cliché to diversify the tourism products from the arena of travel and tourism. Co-ordinated services can also be termed as an all-inclusive package offered by travel facilitators to the medical tourist which includes transportation, transfers, medical treatment, holidaying, leisure and all allied services. (Gan, James \& Frederick 2011).

Medical tourism in the forefront is backed by the corporate hospitals offering high end infrastructure, medical amenities, allied services and an effective healthcare network with the hospitality sector. The private hospitals that have gone one step ahead in commercializing their services, with high-end sophistication, in the local as well as international market. Globalization and resulting trade liberalization in health services have caused an upsurge in international migration of health care professionals in recent years Greater openness has created new opportunities for these professionals. The General Agreement on Trade in Services (GATS) signed as a part of World Trade Organization (WTO) agreement also provided an opportunity to member countries to explore new markets in health services by further liberalizing trade in services.

\section{Review of Literature}

The literature reviews reflect on various aspects and areas in medical tourism. This covers the prospects of medical tourism, emerging trends and the future of upcoming medical hubs.

Bookman and Bookman (2007), in their book discuss how western patients who are increasingly travelling to developing countries for healthcare are increasingly offered the best skills and facilities to cater to their needs. This international trade in medical services has huge economic potential for developing countries and serious implications for healthcare across the globe. It is successful only in countries with economic and political advantages that enable them to navigate around international and domestic obstacles to trade in medical services.

C. Sack, A. Scherag, et al. (2011) in their article reveal that the countries where hospitals are undergoing accreditation as mandatory or voluntary measures are agrees that accreditations positively influence quality of care and patient satisfaction. The article talks about the relationship between patient satisfaction and accreditation status. The conclusion sustains the notion that hospital accreditation may represent a step towards total quality management, but may not be a key factor for quality of care measured by the patient's willingness to recommend to others.

Billie Ann Brotman (2010) examines demand factors for sophisticated medical treatments offered by private hospitals operating in India. The article determines three types of medical tourism-Outbound, 
Inbound, and Intrabound. It attributes the increased profitability and positive growth trends by private hospital chains to rising domestic income levels within India.

Debra Melani focuses on the growth of medical tourism industry in Colorado. The author states that the healthcare providers are expanding on medical tourism aiming to attract more patients to the state. Medical tourism also helps employers reduce medical expenses while offering employees a wider range of treatment.

Today, India, Thailand, Singapore and Hong Kong are considered as popular medical travel destinations. For negotiating in the world of discounted medical care, an entire industry of middlemen has sprung up. Though the options are seemingly endless, buyers ought to beware of issues pertaining to quality.

E, Tilman, G Ceani et al. (2010) in their article discuss the economic geography of medical tourism and a survey of healthcare consumer preferences. While medical tourism is sometimes oriented towards cost savings, it is frequently a matter of accessing innovative procedures without spending time on waiting lists.

\section{Concept of the Study}

Healthcare service industry is one of the flourishing sectors of the Indian economy. Lifestyle diseases have emerged from the demanding and hectic pace of life led by people today. There is thus a need to de-stress and increase involvement in leisure activities. Increase in awareness to keep oneself healthy coupled with rise in standard of living have led to increase in demand for quality healthcare services. Thus, the research focuses on the prospects of the booming medical sector coupled with the growing hospitality sector considering four prominent cities of South India and highlighting the scope and growth of medical tourism and increasing the visibility of India in the global map as a medical tourism hub.

\section{Need of the Study}

Although, India is a recent entrant into the medical tourism arena, it is poised to emerge as a major global player. India offers worldclass healthcare that costs substantially less than those in developed countries, using the same technology delivered by competent specialists attaining similar success rates. Further the necessity is towards creation of an effective value creation network and healthcare environment thereby building professional competency through healthcare manageRs The study is necessitated by the role played by the hospitality sector in promoting medical tourism in coordination with the healthcare sector. Considering all these factors it is imperative to undertake this study of the various independent variables that impact the growth of medical tourism in south India.

\section{Research Methodology}

The process of research includes two broad segments of data collection. The primary data was gathered through structured questionnaires and interviews from the service providers and medical tourists. The secondary data was gathered from libraries of research centres, universities, and management institutes by referring to books, journals, magazines, travel guides, travelogues, and monographs.

\section{Objectives}

The research was conducted with the following objectives:

- To determine the correlation between quality and standardization norms and the demand for medical tourism in South India.

- To identify the degree of balance between the quality of assured services and co-ordinated services that is allied to the hospitality industry. 


\section{Hypotheses}

The following study had two hypotheses which were tested that there is a significant role for quality and standardization norms and the demand for medical tourism and there is a significant relationship between co-ordinated service and the brand image portrayed in the international market.

\section{Sampling Technique}

The procedure for sampling adopted for the research is nonprobability sampling technique namely judgmental sampling as the items for the sample are selected deliberately; since the choice concerning the items remains supreme. However, the limitation is that there is no assurance that every element has some specifiable chance of being included.

Table 1. Sample Distribution

\begin{tabular}{|l|c|}
\hline \multicolumn{1}{|c|}{ Sample Size-International Patients } & 140 nos \\
\hline No. of Hospitals Visited & 30 nos \\
\hline Types of Hospitals & 26 \\
Corporate or Private Hospitals & 01 \\
Medical Institutions & 01 \\
Government Hospitals & 02 \\
Alternative Treatment Centres & \\
(Wellness and Ayurveda) & \\
\hline Hospitals Visited in South India & 08 \\
Andhra Pradesh (Hyderabad) & 07 \\
Tamil Nadu (Chennai) & 07 \\
Karnataka (Bangalore) & 08 \\
Kerala (Calicut, Cochin and Trivandrum) & \\
\hline
\end{tabular}

\section{Testing of Hypotheses}

Hypotheses 1 - Significant Role for Quality and Standardization Norms and Demand for Medical Tourism

$\mathrm{HO}$ : There is no significant role for quality and standardization norms and demand for medical tourism.

$\mathrm{H} 1$ : There is a significant role for quality and standardization norms and demand for medical tourism.

Table 2. Result of Chi-Square Test on Significant Factors for Quality Assurance

\begin{tabular}{|l|r|r|r|r|r|r|}
\hline \multirow{2}{*}{ Quality Assurance Factors } & \multicolumn{4}{|c|}{ Location } & \multirow{2}{*}{ C cal $^{*}$ p-value } \\
\cline { 2 - 6 } & Kerala & Bangalore & Hyderabad & Chennai & & \\
\hline Hospital Accreditation & $40.00 \%$ & $40.00 \%$ & $31.43 \%$ & $48.57 \%$ & 2.1429 & 0.5433 \\
\hline Hospital Affiliation & $3.33 \%$ & $0.00 \%$ & $0.00 \%$ & $0.00 \%$ & 3.6930 & 0.2966 \\
\hline Physician's Credentials & $50.00 \%$ & $65.00 \%$ & $74.29 \%$ & $74.29 \%$ & 5.6051 & 0.1325 \\
\hline Online Communities & $10.00 \%$ & $17.50 \%$ & $14.71 \%$ & $11.43 \%$ & 1.0200 & 0.7964 \\
\hline Goodwill & $0.00 \%$ & $2.50 \%$ & $2.86 \%$ & $8.57 \%$ & 3.8370 & 0.2796 \\
\hline
\end{tabular}

\section{Interpretation}

The above analysis represents that there is no difference in the importance of different parameters of quality assurance amongst the different medical tourism destinations. The above analysis projects the p-value, which is more than $5 \%$ and hence, there are no significant differences in the factors to be considered for quality assurarice, amongst the locations, and the null hypothesis are accepted.

Hypotheses 2-Significant Relationship between Co-ordinated Service and the Brand Image Portrayed in the International Market

H0: There is no significant relationship between co-ordinated service and the brand image portrayed in the international market. 
H1: There is a significant relationship between co-ordinated service and the brand image portrayed in the international market.

Table 3. Result of Chi-Squared Test on Factors Affecting the Accessibility of Co-ordinated Services

\begin{tabular}{|c|c|c|c|c|c|c|}
\hline \multirow{2}{*}{ Types of Factors } & \multicolumn{4}{|c|}{ Location } & \multirow{2}{*}{$x^{2}$ cal } & \multirow{2}{*}{ p-value } \\
\hline & Kerala & Bangalore & Hyderabad & Chennai & & \\
\hline Lack of Co-ordination & $13.33 \%$ & $37.50 \%$ & $34.29 \%$ & $37.14 \%$ & 5.9051 & 0.1163 \\
\hline Delayed Response & $63.33 \%$ & $50.00 \%$ & $45.71 \%$ & $40.00 \%$ & 3.7627 & 0.2883 \\
\hline Poor Networking & $3.33 \%$ & $7.50 \%$ & $2.86 \%$ & $20.00 \%$ & 8.4006 & 0.0384 \\
\hline $\begin{array}{l}\text { Inefficiency in } \\
\text { Troubleshooting }\end{array}$ & $3.33 \%$ & $7.50 \%$ & $11.43 \%$ & $0.00 \%$ & 4.7948 & 0.1875 \\
\hline Poor Follow-up & $26.67 \%$ & $15.00 \%$ & $11.43 \%$ & $22.86 \%$ & 3.2434 & 0.3556 \\
\hline Rigid Procedures & $0.00 \%$ & $0.00 \%$ & $2.86 \%$ & $0.00 \%$ & 3.0216 & 0.3883 \\
\hline
\end{tabular}

\section{Interpretation}

The above analysis represents that there were significant differences in the perception of poor networking affecting the accessibility of coordinated services amongst the locations; hence, the null hypothesis could be rejected. Poor networking as a factor affecting accessibility of co-ordinated services was perceived to be the highest amongst respondents coming to Chennai for treatment, and the lowest amongst respondents coming to Hyderabad for treatment. There were no significant differences in the perception of other factors affecting the accessibility of co-ordinated services amongst the locations and hence the null hypothesis is accepted.

\section{Outcomes of the Study}

The study envisages certain challenges facing healthcare organizations in South India. An integrated approach to the management of quality, drawing upon the interrelationships between quality and productivity, and between quality and technology is one of the pivotal challenges for South India. To ascertain the interrelationships, a total quality management triangle is proposed in Figure 1. Many experts agree that quality improvement leads to productivity increase. This relationship is not fully accepted in the healthcare segment; though many believe that one mode of establishing quality is by huge capital investments in elaborate and sophisticated technologies. Healthcare administrators are often misled into spending huge amount of money without first giving a chance to small but continuous improvements. It amounts to a policy of buying "quality" through costly technology related improvements, as opposed to small but steady, more costefficient and deliberate improvement efforts involving employees. The concept of continuous improvement strategy for quality implies that quality is a process rather than an outcome. Technology can be used to support quality and productivity through the use of information systems.

Another prime challenge for South India is to be cognizant about a complete service quality management as it is recently that healthcare organizations are showing concern over issues such as quality, cost and competitiveness. The imperatives of competition dictate that a hospital whose current status is poor must improve rapidly for its survival. One whose status is superior must improve to preserve its competitive edge, and a hospital which is average must improve to prevent its status from regressing to poor and to make it superior.

The relationships linking total service quality management, productivity and technology becomes evident as the present theories and tools of TSQM are considered. Total service quality control (TSQC) is a business management philosophy, which, when applied to healthcare organizations in South India which seeks to provide healthcare customers with satisfaction through quality in the services provided. It is a practical approach to enhance quality management based on facts, and involves all the employees of the organization including, CEO, administrators, nursing, medicine, technical and clinical employees. It is supported by several administrative 
processes, including quality control teams, policy developments, cross-functional management, and quality in routine activities.

Quality control teams are healthcare employees who are trained, organized, and structured groups which identify problems and brainstorm for causes and solutions. Policy development is a process in which management works together to focus resources on achieving customer satisfaction for patients and other customeRs Cross-functional management is a necessary interdepartmental activity aimed to achieve corporate objectives such as, quality, cost, and delivery. Quality in routine activities is a decentralized procedure for controlling and improving routine work thereby, to standardize routine activities such as, making a patients database, and administering routine medication.

Application of quality control systems is a vital aspect that hospitals in South India cannot disregard. It would lead the South in a new direction by ensuring quality and enhancing customer satisfaction.

Figure 1. Total Quality Management Matrix in Healthcare Sector

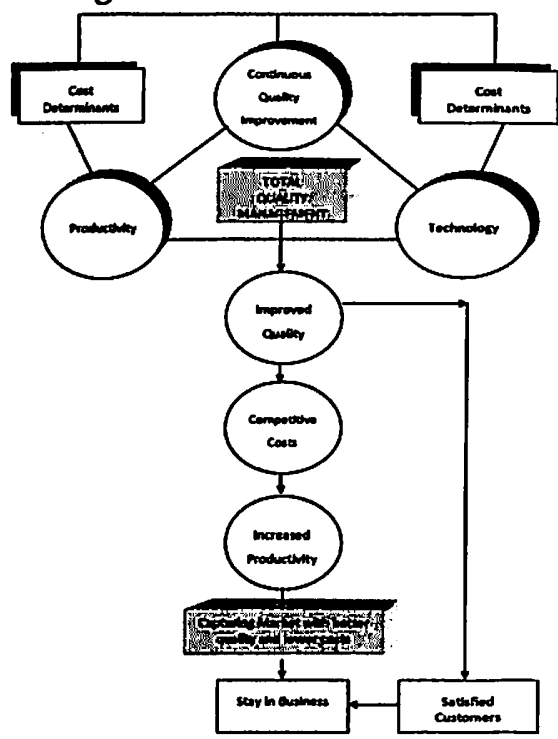

\section{General Findings}

1. Understandably, the overall perception of the quality of service of the assured services and that of the co-ordinated services were high and were positively correlated. Further analysis confirms that the overall perception of the quality of service of assured services is significantly higher than the overall perception of the service quality of the co-ordinated services.

2. The research determines that there were significant differences in the overall perception of the service quality offered and the overall level of satisfaction with associated and co-ordinated services amongst the locations. It was perceived that a lesser ratio of medical tourists preferred the services of medical facilitatoRs

3. The research confirms that there is no difference in the importance of different parameters of quality assurance amongst the different medical tourism destinations and hence, there are no significant differences in the factors to be considered for quality assurance amongst the locations. It was understood that the medical patrons considered a physician's credentials as the predominant factor in assuring quality in comparison to hospital accreditation and affiliations.

4. The study also confirms the most important factors perceived by hospitals for quality assurance are physicians' credentials, global competency, and accreditations. Online communities, word-ofmouth, and affiliations were also moderately important.

5. The study confirms that the various parameters like travel assistance, language translators, co-ordinated services, cost transparency, post-operative care, insurance assistance and first-aid at the airport are offered by the hospitals to differentiate themselves from their competitors. 


\section{Suggestions}

The stakeholders in medical tourism, i.e., hospital authorities, hospitality industry, policy makers and other intermediaries can consider the following suggestions for building professional competency and a better healthcare management and thereby reduce their perplexities to keep with a trend of quality assurance, quality service and service proficiency.

1. A new paradigm in healthcare segment gives a broader space for the government to play the role of healthcare facilitator with effective trade policies to ensure a seamless value chain.

2. Indian healthcare businesses are receiving medical tourists from developing countries who travel for proficient medical procedures with cost and surgical competency being the prime focus. The policy makers need to focus on this segment and eye a larger share of this market to reposition India as a premium up-market medical hub.

3. Homogeneity in medical aspirants and heterogeneity in medical services demanded would be challenging for South India from the healthcare providers perspective. It also gives a bright prospect for better servicing when each hospital targets a segment with some USP. They must engage with source communities, healthcare systems and governments over a longer period of time thereby specializing in handling customers from specifically targeted regions and for specific products. Knowledge of markets, consumers and channel partners over a period of time would allow competitive advantage.

4. The administrative authorities should undertake capacity building programmes to train the subsidiary division in the medical tourism frameworki.e. the paramedical and non-medical staff of the service providers who occasionally come across barriers of cross-cultural sensitivities.
5. The South Indian healthcare segment can also focus on alternative forms of treatment like ayurveda, unani, and siddha to tap the potential global market thereby creating a niche for itself.

6. The private hospitals can network with the international embassies and the government to attract the government funded medical tourists thereby globalizing its healthcare services.

7. The stakeholders in South India can explore exhibitions, trade fairs and associations with international bodies to enhance its medical tourism.

8. The healthcare segment can flourish effectively if the hospital managers are directly involved in promoting healthcare services in the global market, thereby, leaving no space for further ambiguity in the minds of the medical aspirants.

\section{Scope for Further Research}

The arena of medical tourism can be transversely diagnosed to foster the prospects of medical tourism with the changing market expectations. The following areas could be considered for further research in medical tourism:

1. The gap pertaining to the medical tourist's expectations and the relevance in the value chain of healthcare network.

2. The complexity in rules and norms followed internationally and the influences on the medical tourists' decision in travelling abroad for medical treatments.

3. Identifying the medical tourist's scepticism about medical ethics or code of ethics and the prime concerns of medical tourists visiting India. 


\section{Conclusion}

The prospects of medical tourism have radically changed with the divergent role played by the stakeholders over the yeaRs Among the healthcare providers, the most predominant stake holder offering a kaleidoscope of services and amenities catering to the needs of the 'new medical tourist' is the healthcare manageRs The increased competition and the growth of medical tourism have pulled various other stakeholders into the trade. Predominantly, the policy makers, community and other private participants have played a significant role in globalizing the South Indian healthcare systems. Equally challenging is the cultural and regulatory barriers, which can significantly affect the healthcare globalization in Southern India. Proficiency in delivering healthcare services and lesser perplexity in the healthcare network can enhance the capacity building process. Quality and standard assurance are some major parameters in benchmarking the healthcare medical hubs and helping them to prosper.

\section{References}

Bookman, M. Z., \& Bookman, K. R. (2007). Medical tourism in developing countries. United Kingdom: Palgrave Macmilan.

Brotman, B. A. (2010). Medical tourism private hospitals: Focus India. Journal of Health Care Finance, 37(1), 45-50.

Ehrbeck, T., Guevara, C., Mango, P. D., Cordina, R., \& Singhal, S. (2008). Health care and the consumer. McKinsey Quarterly, 4, 80-91.

Gan, L., \& Frederick, J. R. (2011). Medical tourism facilitators: Patterns of service differentiation, Journal of Vacation Marketing, 17(3), 165-183.

Juran, J. M., \& Godfrey, A. B. (1999). Juran's quality handbook. New York: McGraw-Hill.

Melani, \& Debra. (2011). Chasing the best deal for health, ColoradoBiz, 38(6), 76-79.
Sack, C., Scherag, A., LuTkes, P., GuNther, W., H.JoCkel, K., \& Holtmann, G. (2011). Is there an association between hospital accreditation and patient satisfaction with hospital care? A survey of 37000 patients treated by 73 hospitals, International Joumal for Quality in Health Care, 23(3), 278-283

Theobald, F.T. (1998). The meaning, scope and measurement of travel and tourism. Oxford: Butterworth - Heinemann.

Woodman, J. (2007). Patients beyond borders: Everybod'ys guide to affordable, world-class medical tourism. (1 ed.). Durham: Healthy Travel Media. 